\title{
LA INTELIGENCIA EMOCIONAL COMO UNA HABILIDAD ESENCIAL EN LA ESCUELA
}

\section{Pablo Fernández-Berrocal y Natalio Extremera Pacheco}

Universidad de Málaga, España

Nuestra sociedad ha valorado de forma pertinaz durante los últimos siglos un ideal muy concreto del ser humano: la persona inteligente. En la escuela tradicional, se consideraba que un niño era inteligente cuando dominaba las lenguas clásicas, el latín o el griego, y las matemáticas, el álgebra o la geometría. Más recientemente, se ha identificado al niño inteligente con el que obtiene una puntuación elevada en los tests de inteligencia. El cociente intelectual $(\mathrm{Cl})$ se ha convertido en el referente de este ideal y este argumento se sustenta en la relación positiva que existe entre el $\mathrm{Cl}$ de los alumnos y su rendimiento académico: los alumnos que más puntuación obtienen en los tests de $\mathrm{Cl}$ suelen conseguir las mejores calificaciones en la escuela.

En el siglo XXI esta visión ha entrado en crisis por dos razones. Primera, la inteligencia académica no es suficiente para alcanzar el éxito profesional. Los abogados que ganan más casos, los médicos más prestigiosos y visitados, los profesores más brillantes, los empresarios con más éxito, los gestores que obtienen los mejores resultados no son necesariamente los más inteligentes de su promoción. No son aquellos adolescentes que siempre levantaban primero la mano en la escuela cuando preguntaba el profesor o resaltaban por sus magníficas notas académicas en el instituto. No son aquellos adolescentes que se quedaban solos en el recreo mientras los demás jugaban al fútbol o simplemente charlaban. Son los que supieron conocer sus emociones y cómo gobernarlas de forma apropiada para que colaboraran con su inteligencia. Son los que cultivaron las relaciones humanas y los que conocieron los mecanismos que motivan y mueven a las personas. Son los que se interesaron más por las personas que por las cosas y que entendieron que la mayor riqueza que poseemos es el capital humano.

Segunda, la inteligencia no garantiza el éxito en nuestra vida cotidiana. La inteligencia no facilita la felicidad ni con nuestra pareja, ni con nuestros hijos, ni que tengamos más y mejores amigos. El $\mathrm{Cl}$ de las personas no contribuye a nuestro equilibrio emocional ni a nuestra salud mental. Son otras habilidades emocionales y sociales las responsables de nuestra estabilidad emocional y mental, así como de nuestro ajuste social y relacional.

En este contexto es en el que la sociedad se ha hecho la pregunta: ¿por qué son tan importantes las emociones en la vida cotidiana? La respuesta no es fácil, pero ha permitido que estemos abiertos a otros ideales y modelos de persona.

En este momento de crisis ya no vale el ideal exclusivo de la persona inteligente y es cuando surge el concepto de inteligencia emocional (IE) como una alternativa a la visión clásica.

En la literatura científica existen dos grandes modelos de IE: los modelos mixtos y el modelo de habilidad. Los modelos mixtos combinan dimensiones de personalidad como el optimismo y la capacidad de 
automotivación con habilidades emocionales (Goleman y Bar-On). En nuestro país, el que ha tenido más difusión en los contextos educativos ha sido el modelo mixto de inteligencia emocional de Daniel Goleman. Fenómeno que tiene que ver más con las razones del marketing y la publicidad, que con la lógica de la argumentación científica.

El propósito de este artículo es ilustrar el modelo de habilidad de John Mayer y Peter Salovey, menos conocido en nuestro entorno, pero con un gran apoyo empírico en las revistas especializadas. De hecho, Goleman tomó el concepto de IE de un artículo de Mayer y Salovey del año 1990, aunque en su famoso libro le da un enfoque bastante diferente.

El modelo de habilidad de Mayer y Salovey se centra de forma exclusiva en el procesamiento emocional de la información y en el estudio de las capacidades relacionadas con dicho procesamiento. Desde esta teoría, la IE se define como la habilidad de las personas para atender y percibir los sentimientos de forma apropiada y precisa, la capacidad para asimilarlos y comprenderlos de manera adecuada y la destreza para regular y modificar nuestro estado de ánimo o el de los demás. Desde el modelo de habilidad, la IE implica cuatro grandes componentes:

- Percepción y expresión emocional: reconocer de forma consciente nuestras emociones e identificar qué sentimos y ser capaces de darle una etiqueta verbal.

- Facilitación emocional: capacidad para generar sentimientos que faciliten el pensamiento.

- Comprensión emocional: integrar lo que sentimos dentro de nuestro pensamiento y saber considerar la complejidad de los cambios emocionales.

- Regulación emocional: dirigir y manejar las emociones tanto positivas como negativas de forma eficaz.

Estas habilidades están enlazadas de forma que para una adecuada regulación emocional es necesaria una buena comprensión emocional y, a su vez, para una comprensión eficaz requerimos de una apropiada percepción emocional.

No obstante, lo contrario no siempre es cierto. Personas con una gran capacidad de percepción emocional carecen a veces de comprensión y regulación emocional.

Esta habilidad se puede utilizar sobre uno mismo (competencia personal o inteligencia intrapersonal) o sobre los demás (competencia social o inteligencia interpersonal). En este sentido, la IE se diferencia de la inteligencia social y de las habilidades sociales en que incluye emociones internas, privadas, que son importantes para el crecimiento personal y el ajuste emocional.

Por otra parte, los aspectos personal e interpersonal también son bastante independientes y no tienen que darse de forma concadenada. Tenemos personas muy habilidosas en la comprensión y regulación de sus emociones y muy equilibradas emocionalmente, pero con pocos recursos para conectar con los demás. Lo contrario también ocurre, pues hay personas con una gran capacidad empática para comprender a los demás, pero que son muy torpes para gestionar sus emociones. 
La inteligencia emocional, como habilidad, no se puede entender tampoco como un rasgo de personalidad o parte del "carácter» de una persona. Observemos a un individuo que tiene como característica de su personalidad ser extravertido, ¿podremos pronosticar el grado de inteligencia emocional personal o interpersonal que posee? Realmente, no podemos pronosticarlo. Otra cosa es que exista cierta interacción entre la IE y la personalidad, al igual que existe con la inteligencia abstracta: ¿utilizará y desarrollará igual una persona su inteligencia emocional con un $\mathrm{Cl}$ alto o bajo? En este sentido, las personas con cierto tipo de personalidad desarrollarán con más o menos facilidad, con mayor o menor rapidez, sus habilidades emocionales. Al fin y al cabo, la persona no es la suma de sus partes, sino una fusión que convive -milagrosamente- de forma integrada.

Vamos a desarrollar con brevedad estos cuatro componentes.

\section{PERCEPCIÓN Y EXPRESIÓN EMOCIONAL}

Los sentimientos son un sistema de alarma que nos informa sobre cómo nos encontramos, qué nos gusta o qué funciona mal a nuestro alrededor con la finalidad de realizar cambios en nuestras vidas. Una buena percepción implica saber leer nuestros sentimientos y emociones, etiquetarlos y vivenciarlos. Con un buen dominio para reconocer cómo nos sentimos, establecemos la base para posteriormente aprender a controlarnos, moderar nuestras reacciones y no dejarnos arrastrar por impulsos o pasiones exaltadas. Ahora bien, ser conscientes de las emociones implica ser hábil en múltiples facetas tintadas afectivamente. Junto a la percepción de nuestros estados afectivos, se suman las emociones evocadas por objetos cargados de sentimientos, reconocer las emociones expresadas, tanto verbal como gestualmente, en el rostro y cuerpo de las personas; incluso distinguir el valor o contenido emocional de un evento o situación social.

Por último, la única forma de evaluar nuestro grado de conciencia emocional está siempre unida a la capacidad para poder describirlos, expresarlos con palabras y darle una etiqueta verbal correcta. No en vano, la expresión emocional y la revelación del acontecimiento causante de nuestro estrés psicológico se alzan en el eje central de cualquier terapia con independencia de su corriente psicológica.

\section{FACILITACIÓN EMOCIONAL}

La razón y la pasión parecen aspectos opuestos en nuestra vida. Durante siglos, filósofos y científicos han puesto en duda su carácter interactivo y de ayuda recíproca. Las emociones y los pensamientos se encuentran fusionados sólidamente $y$, si sabemos utilizar las emociones al servicio del pensamiento, nos ayudan a razonar de forma más inteligente y tomar mejores decisiones. Tras una década de investigación, empezamos a descubrir que dominar nuestras emociones y hacerlas partícipes de nuestros pensamientos favorece una adaptación más apropiada al ambiente. Por ejemplo, nuestras emociones se funden con nuestra forma de pensar consiguiendo guiar la atención a los problemas 
realmente importantes, nos facilita el recuerdo de eventos emotivos, permite una formación de juicios acorde a cómo nos sentimos y, en función de nuestros sentimientos, tomamos perspectivas diferentes ante un mismo problema. Por otra parte, el «cómo nos sentimos» guiará nuestros pensamientos posteriores, influirá en la creatividad en el trabajo, dirigirá nuestra forma de razonar y afectará a nuestra capacidad diaria de deducción lógica. En efecto, que nuestros alumnos estén felices o tristes, enfadados o eufóricos o hagan o no un uso apropiado de su IE para regular y comprender sus emociones puede, incluso, determinar el resultado final de sus notas escolares y su posterior dedicación profesional.

\section{COMPRENSIÓN EMOCIONAL}

Para comprender los sentimientos de los demás debemos empezar por aprender a comprendernos a nosotros mismos, cuáles son nuestras necesidades y deseos, qué cosas, personas o situaciones nos causan determinados sentimientos, qué pensamientos generan tales emociones, cómo nos afectan y qué consecuencias y reacciones nos provocan. Si reconocemos e identificamos nuestros propios sentimientos, más facilidades tendremos para conectar con los del prójimo. Empatizar consiste «simplemente» en situarnos en el lugar del otro y ser consciente de sus sentimientos, sus causas y sus implicaciones personales. Ahora bien, en el caso de que la persona nunca haya sentido el sentimiento expresado por el amigo, le resultará difícil tratar de comprender por lo que está pasando. Aquél que nunca ha vivido una ruptura de pareja, en ningún momento fue alabado y reforzado por sus padres por un trabajo bien hecho o jamás ha sufrido la perdida de un ser querido realizará un mayor esfuerzo mental y emocional de la situación, aun a riesgo de no llegar a entenderlo finalmente, para imaginarse el estado afectivo de la otra persona. Junto a la existencia de otros factores personales y ambientales, el nivel de IE de una persona está relacionado con las experiencias emocionales que nos ocurren a lo largo del ciclo vital.

Desarrollar una plena destreza empática en los niños implica también enseñarles que no todos sentimos lo mismo en situaciones semejantes y ante las mismas personas, que la individualidad orienta nuestras vidas y que cada persona siente distintas necesidades, miedos, deseos y odios.

\section{REGULACIÓN EMOCIONAL}

Una de las habilidades más complicadas de desplegar y dominar con maestría es la regulación de nuestros estados emocionales. Consiste en la habilidad para moderar o manejar nuestra propia reacción emocional ante situaciones intensas, ya sean positivas o negativas. La regulación emocional se ha considerado como la capacidad para evitar respuestas emocionales descontroladas en situaciones de ira, provocación o miedo. Tal definición es comúnmente considerada correcta, pero resulta incompleta. Las investigaciones están ampliando el campo de la autoregulación a las emociones positivas. Una línea divisoria invisible y muy frágil demarca los límites entre sentir una emoción y dejarse llevar por ella. Es decir, regular las emociones implica algo más que simplemente alcanzar satisfacción con los sentimientos positivos y tratar de evitar y/o esconder nuestros afectos más nocivos. La regulación supone un paso más allá, consiste en percibir, sentir y vivenciar nuestro estado afectivo, sin ser abrumado o avasallado por él, de 
forma que no llegue a nublar nuestra forma de razonar. Posteriormente, debemos decidir de manera prudente y consciente, cómo queremos hacer uso de tal información, de acuerdo a nuestras normas sociales y culturales, para alcanzar un pensamiento claro y eficaz y no basado en el arrebato y la irracionalidad. Un experto emocional elige bien los pensamientos a los que va a prestar atención con objeto de no dejarse llevar por su primer impulso e, incluso, aprende a generar pensamientos alternativos adaptativos para controlar posibles alteraciones emocionales. Del mismo modo, una regulación efectiva contempla la capacidad para tolerar la frustración y sentirse tranquilo y relajado ante metas que se plantean como muy lejanas o inalcanzables. Tampoco se puede pasar por alto la importancia de la destreza regulativa a la hora de poner en práctica nuestra capacidad para automotivarnos. En este sentido, el proceso autoregulativo forma parte de la habilidad inherente para valorar nuestras prioridades, dirigir nuestra energía hacia la consecución de un objetivo, afrontando positivamente los obstáculos encontrados en el camino, a través de un estado de búsqueda, constancia y entusiasmo hacia nuestras metas.

\section{CONCLUSIÓN}

El propósito de este artículo ha sido sensibilizar a los educadores sobre la importancia de la educación explícita de las emociones y de los beneficios personales y sociales que conlleva.

Hasta hace relativamente poco tiempo cuando se revisaba la bibliografía sobre cómo deben educar los profesores, se enfatizaba el aprendizaje y la enseñanza de modelos de conductas correctas y pautas de acción deseables en una relación. Escasa mención se daba a los sentimientos y emociones generadas por uno y otro. Es decir, la tendencia arraigada era la de manejar $y$, hasta cierto punto controlar, el comportamiento de nuestros alumnos sin atender a las emociones subyacentes a tales conductas. Nuestra postura en consonancia con la del modelo de inteligencia emocional de Mayer y Salovey de habilidad es algo distinta. Debemos comprender y crear en nuestros adolescentes una forma inteligente de sentir, sin olvidar cultivar los sentimientos de padres y educadores $\mathrm{y}$, tras ello, el comportamiento y las relaciones familiares y escolares irán tornándose más equilibradas.

Por otra parte, la enseñanza de emociones inteligentes depende de la práctica, el entrenamiento y su perfeccionamiento y, no tanto, de la instrucción verbal. Ante una reacción emocional desadaptativa de poco sirve el sermón o la amenaza verbal de «no lo vuelvas a hacer». Lo esencial es ejercitar y practicar las capacidades emocionales desglosadas en el artículo y convertirlas en una parte más del repertorio emocional del niño. De esta forma, técnicas como el modelado y el role-playing emocional se convierten en herramientas básicas de aprendizaje a través de las cuales los educadores, en cuanto «expertos emocionales», materializan su influencia educativa, marcan las relaciones socioafectivas y encauzan el desarrollo emocional de sus alumnos.

Acorde con lo expuesto, la escuela tendrá en el siglo XXI la responsabilidad de educar las emociones de nuestros hijos tanto o más que la propia familia. La inteligencia emocional no es sólo una cualidad individual. Las organizaciones y los grupos poseen su propio clima emocional, determinado en gran parte por la habilidad en IE de sus líderes. En el contexto escolar, los educadores son los principales 
líderes emocionales de sus alumnos. La capacidad del profesor para captar, comprender y regular las emociones de sus alumnos es el mejor índice del equilibrio emocional de su clase.

En este momento de fuerte debate sobre los cambios educativos, sería una buena ocasión para reflexionar sobre la inclusión de las habilidades emocionales de forma explícita en el sistema escolar. Porque el profesor ideal para este nuevo siglo tendrá que ser capaz de enseñar la aritmética del corazón y la gramática de las relaciones sociales. Si la escuela y la administración asumen este reto, dotando de la formación pertinente a los educadores, hará que la convivencia en este milenio sea más fácil para todos y que nuestro corazón no sufra más de lo necesario.

\section{REFERENCIAS BIBLIOGRÁFICAS DE INTERÉS}

En este apartado recogemos alguna de la bibliografía actual que nos ha parecido más relevante para aquellos lectores interesados en profundizar en el campo de la inteligencia emocional, su educación y desarrollo.

Bibliografía en español:

- EliAs, M.; TobIAS, S., y FRIEDlANDer, B. (1999): Educar con inteligencia emocional. Barcelona, Plaza y Janés.

- Fernández-Berrocal, P.; Salovey, P.; Vera, A.; Ramos, N., y Extremera, N. (2001): «Cultura, inteligencia emocional percibida y ajuste emocional: un estudio preliminar», en: Revista Electrónica de Motivación y Emoción, 4.

- Fernández-BerRocal, P., y RAmos, N. (2002). Corazones Inteligentes. Barcelona, Kairós.

- GARDNER, H. (2001): La inteligencia reformulada. Barcelona, Paidós.

- GolemAN, D. (1996): Inteligencia emocional. Barcelona, Kairós.

- GotTmAn, J., y DeClaiRE, J. (1997): Los mejores padres. Madrid, Javier Vergara.

- GüELL, M., y MuÑOZ, J. (1999): Desonócete a ti mismo. Programa de alfabetización emocional. Barcelona, Paidos.

- SHAPIRO, L. E. (1997): La inteligencia emocional en niños. Madrid, Javier Vergara.

- Sternberg, R. (1997): La inteligencia exitosa. Barcelona, Paidós.

- VAllÉs, A., y VALLÉs, C. (2000): Inteligencia emocional: Aplicaciones educativas. Madrid, Editorial EOS.

Bibliografía en inglés:

- BAR-ON, R., y PARKER, J. (2001): The Handbook of Emotional Intelligence. Theory, developmental, and application at home, school, and in the workplace. San Francisco, Jossey-Bass.

- CIARROCHI, J.; Forgas, J., y MAYER, J. (2001): Emotional Intelligence in Everyday Life: A Scientific Inquiry. Nueva York, Psychology Press.

- Salover, P., y SluYter, D. (1997): Emotional Development and Emotional Intelligence: Implications for Educators. Nueva York, Basic Books. 


\title{
Contactar
}

Revista lberoamericana de Educación

\author{
Principal OEI
}

